\title{
CENÁRIO DA DOAÇÃO DE ÓRGÃOS EM UMA MACRORREGIONAL DE PERNAMBUCO
}

\author{
ORGAN DONATION SCENARIO IN A \\ TRANSPLANTATION CENTER OF PERNAMBUCO
}

\section{ESCENARIO DE LA DONACIÓN DE ÓRGANOS EN UNA CENTRAL DE PERNAMBUCO}

\author{
Christielle Lidiane Alencar Marinho ${ }^{1}$ \\ Ana Isabel Cezário de Carvalho Conceição ${ }^{2}$ \\ Alana Mirelle Coelho Leite ${ }^{3}$ \\ Joice Requião Costa de Santana ${ }^{4}$ \\ Flávia Emília Cavalcanti Valença Fernandes ${ }^{5}$
}

\begin{abstract}
Como citar este artigo: Marinho CLA, Conceição AICC, Leite AMC, Santana JRC, Fernandes FECV. Cenário da doação de órgãos em uma macrorregional de Pernambuco. Rev baiana enferm. 2019;33:e33664.

Objetivo: conhecer o cenário da doação de órgãos e tecidos de uma macrorregional de transplantes situada em Pernambuco. Método: estudo quantitativo, descritivo, retrospectivo e exploratório. Resultados: suspeita de morte encefálica identificada em 524 prontuários de pacientes internados entre janeiro de 2013 e dezembro de 2017. A maioria dos potenciais doadores era do sexo masculino (63,6\%), faixa etária entre 21 e 60 anos (55,9\%); principais causas de morte encefálica foram acidente vascular encefálico (27,9\%) e trauma cranioencefálico (19,5\%). Maioria de internamentos $(96,2 \%)$ em instituições públicas. Protocolos de morte encefálica totalizaram 86,8\%. Predominou aceitação familiar $(53,5 \%)$ para doação. Conclusão: doação de órgãos e tecidos em uma macrorregional de transplantes era feita majoritariamente por indivíduos do sexo masculino, adultos jovens, atendidos em hospitais públicos e tendo como principal causa de morte o traumatismo crânio encefálico. Quanto ao aceite para doação, as entrevistas familiares foram positivas e, em grande parte, favoráveis à doação.
\end{abstract}

Descritores: Doadores de Tecidos. Obtenção de Tecidos e Órgãos Avaliação em Saúde. Morte Encefálica.

Objective: to know the scenario of organ and tissue donation of a transplantation center located in Pernambuco. Method: quantitative, descriptive, retrospective and exploratory study. Results: suspected brain death identified in 524 medical records of patients hospitalized between January 2013 and December 2017. Most potential donors were male (63.6\%), age group between 21 and 60 years old (55.9\%); main causes of brain death were stroke (27.9\%) and head trauma (19.5\%). Most of hospitalizations (96.2\%) in public institutions. Total of brain death protocols $86.8 \%$. Family acceptance (53.5\%) for donation predominated. Conclusion: mostly male individuals, young adults, treated in public hospitals and having traumatic brain injury as the main cause of death, were organ and tissue donors in a transplant center. As for donation acceptance, family interviews were positive and, in large part, in favor of donation.

Descriptors: Tissue Donors. Obtaining Tissues and Organs Health Assessment. Brain Death.

Enfermeira. Mestre em Hebiatria. Professora da Universidade do Estado da Bahia. Senhor do Bonfim, Bahia, Brasil. christiellealencar@yahoo.com.br. https://orcid. org/0000-0002-3827-5494

Enfermeira. Especialista em Urgência e Emergência da Prefeitura Municipal de Senhor do Bonfim. Senhor do Bonfim, Bahia, Brasil. https://orcid.org/0000-0003-25751065

Enfermeira. Mestre em Ciências. Professora da Universidade do Estado Bahia. Senhor do Bonfim, Bahia, Brasil. https://orcid.org/0000-0002-9631-1908

4 Enfermeira. Mestre em Ciências da Saúde. Professora da Universidade do Estado Bahia. Senhor do Bonfim, Bahia, Brasil. https://orcid.org/0000-0002-7264-2956

Enfermeira. Doutora em Inovação Terapêutica. Professora da Universidade Federal de Pernambuco. Petrolina, Pernambuco, Brasil. https://orcid.org/0000-0003-

2840-8561 
Objetivo: conocer el escenario de donación de órganos y tejidos de un centro de trasplantes ubicado en Pernambuco. Método: estudio cuantitativo, descriptivo, retrospectivo y exploratorio. Resultados: sospecha de muerte cerebral identificada en 524 registros médicos de pacientes hospitalizados entre enero de 2013 y diciembre de 2017. La mayoria de los donantes potenciales eran varones (63,6\%), de edad entre 21 y 60 años (55,9\%); las principales causas de muerte cerebral fueron accidente cerebrovascular (27,9\%) y traumatismo craneoencefálico (19,5\%). La mayoría de las hospitalizaciones (96,2\%) en instituciones públicas. Los protocolos de muerte cerebral totalizaron el 86,8\%. Predominó la aceptación familiar (53,5\%) para la donación. Conclusión: la donación de órganos y tejidos en un centro de trasplante fue realizada principalmente por individuos masculinos, adultos jóvenes, tratados en hospitales públicos y con traumatismo craneoencefálico como la principal causa de muerte. En cuanto a la aceptación de la donación, las entrevistas familiares fueron positivas y, en gran parte, favorables a la donación.

Descriptores: Donantes de tejidos. Obtención de Tejidos y Órganos Evaluación en salud. Muerte Cerebral.

\section{Introdução}

O Brasil ocupa o segundo lugar em números absolutos na realização de transplantes no mundo, dispondo do maior programa público de transplantes de órgãos e tecidos. Nos últimos anos, a taxa de doação vem crescendo e, em 2017, atingiu a meta proposta de 16,5 por milhões de pessoas (pmp), tendo um aumento de 14,6\% em relação ao ano de 2016. Já em 2018, a taxa de doações efetivas aumentou em 2,4\% (17,0 pmp), não atingindo a taxa esperada $(18,0 \mathrm{pmp})^{(1)}$.

Embora os números estejam em crescimento, os transplantes realizados ainda não são suficientes para reduzir a fila de espera. Entre o total de notificações de Potenciais Doadores (PD), em 67\% dos casos a doação não é efetivada, e a recusa familiar é a principal causa $(43 \%)^{(1)}$.

Para que ocorra o processo de doação de órgãos para fins de transplante, é necessária a realização do diagnóstico de Morte Encefálica (ME), com critérios estabelecidos pelo Conselho Federal de Medicina (CFM), em conformidade com a Resolução n. 2.173/2017 ${ }^{(2)}$. A ME é descrita como ausência de atividade supraespinhal, coma não perceptivo e apneia persistente. Após a abertura do protocolo de ME, ocorre a notificação compulsória do potencial doador à Central de Notificação, Captação e Distribuição de Órgãos (CNCDO).

Somente após a confirmação da ME, a doação pode ser oferecida à família que, em conformidade com a Lei n. 10.211/2001, autoriza ou não a doação de órgãos e tecidos ${ }^{(3)}$. Poderá autorizar a doação o cônjuge ou parente, maior de idade, até segundo grau, obedecendo a linha sucessória. Ademais, para que ocorra o enxerto, é necessário que o receptor esteja inscrito em lista única de espera, e que aceite realizar o procedimento, sendo orientado sobre os possíveis riscos e benefícios do procedimento ${ }^{(3)}$.

O potencial doador de órgãos (PD) é o paciente que apresenta condições clínicas suspeitas de ME, inclusive já iniciado o protocolo, de acordo com os critérios pré-estabelecidos pelo $\mathrm{CFM}^{(2)}$. Sequencialmente O PD passará por duas avaliações clínicas e pelo menos um exame complementar, de acordo com a idade, para confirmar ou descartar o diagnóstico de ME. Nesse sentido, serão instauradas medidas de manutenção do PD, visando o fechamento do protocolo e a sobrevida desses órgãos, para que, se confirmada a morte, possa ser oferecida a doação de órgãos ${ }^{(4)}$.

O transplante é caracterizado como uma modalidade terapêutica segura para várias doenças crônicas e incapacitantes, além de promover reabilitação e aumento da expectativa de vida desses indivíduos ${ }^{(1-5)}$. Contudo, para ofertar órgãos de melhor qualidade aos receptores, é necessário intensificar os cuidados com o PD, devido à instabilidade hemodinâmica/fisiológica ocasionada pela ME, o que representa risco de inviabilizar a funcionalidade dos órgãos ${ }^{(6-7)}$.

Os profissionais de saúde ligados ao processo de doação de órgãos, seja na manutenção do PD, seja na equipe de transplantes, precisam conhecer o PD clinicamente e estar em contato 
com seus familiares, para oferecer-lhes assistência de qualidade. A eficácia do transplante depende da efetivação da doação com órgãos de qualidade.

O estudo tem como objetivo conhecer o cenário da doação de órgãos e tecidos de uma macrorregional de transplantes situada em Pernambuco.

\section{Método}

Trata-se de um estudo descritivo, exploratório, de natureza quantitativa, realizada em uma macrorregional de transplantes de Pernambuco, no período de outubro de 2017 a janeiro de 2018.

A macrorregional engloba cerca de $30 \mathrm{mu}-$ nicípios do estado de Pernambuco e tem sua sede em um hospital na cidade de Petrolina (PE), porém recebe as notificações de ME de todos os Hospitais notificadores da Macrorregional.

Foram coletados os dados de todos os prontuários de pacientes internados com suspeita de $\mathrm{ME}$, com protocolo em andamento, do período de janeiro de 2013 a dezembro de 2017, que se enquadraram nos critérios da pesquisa.

Adotados como critérios de inclusão: pacientes potenciais doadores de órgãos, com protocolo em andamento ou concluído. Foram excluídos os prontuários nos quais as anotações estavam incompletas. Após aplicação dos critérios de inclusão e exclusão, foram totalizados 524 prontuários.

Utilizaram-se como instrumentos de coleta de dados a entrevista familiar e um formulário estruturado com questões fechadas, elaborado pelos autores para este estudo, baseado na ficha de notificação do potencial doador, contendo informações referentes ao perfil sociodemográfico, diagnóstico de admissão, comorbidades, diagnóstico clínico de morte encefálica, duração da internação, confirmação de ME e duração do protocolo de ME.

Os dados foram transcritos para o programa Excel for Windows/2013 e depois transpostos para o software Data Analysis and Statistical versão 12.0 , a fim de realizar as análises descritivas, com confecção de tabelas de frequência absolutas e relativas.

O estudo respeitou as exigências formais contidas nas normas nacionais e internacionais regulamentadoras de pesquisas envolvendo seres humanos, conforme Resolução n. 466/2012. Por se tratar de pesquisa com dados secundários, foi solicitada autorização institucional, garantindo a não utilização das informações em prejuízo das pessoas e/ou das comunidades. O projeto foi aprovado pelo Comitê de Ética em Pesquisa da Universidade do Estado da Bahia, sob o Parecer n. 1.984.075 e CAAE n. 65496017.3.0000.0057.

\section{Resultados}

Observa-se que, do total de prontuários analisados, $326(63,6 \%)$ eram de pacientes do sexo masculino; a faixa etária de 41 a 60 anos foi a que predominou, com 177 pacientes $(33,8 \%)$, seguida da faixa etária de 21 a 40 anos, totalizando 168 (32,1\%) dos PD (Tabela 1).

Tabela 1 - Identificação dos potenciais doadores de órgãos e tecidos para transplantes. Macrorregional Petrolina. Petrolina, Pernambuco, Brasil - 2013-2017 (N=524)

\begin{tabular}{l|c|c}
\hline Variáveis & $\mathbf{n}$ & $\mathbf{\%}$ \\
\hline Faixa etária (n=524) & & \\
Até 20 & 102 & 19,5 \\
$21-40$ & 168 & 32,1 \\
$41-60$ & 177 & 33,8 \\
Acima de 61 & 77 & 14,7 \\
Sexo (n=513) & & \\
Masculino & 326 & 63,6 \\
Feminino & 187 & 36,5 \\
\hline
\end{tabular}

Fonte: Elaboração própria. 
Nota-se que as principais causas de morte encefálica foram Trauma Cranioencefálico, com 33,9\% dos casos, seguido de Acidente Vascular Cerebral, com 27,9\% dos casos. Outros diagnósticos, como meningite, hipóxia, malformação arteriovenosa, entre outras causas corresponderam a 16\% das notificações. O tempo de internamento até o diagnóstico definitivo da $\mathrm{ME}$ variou entre menos de 24 horas até 48 horas. Considerando o hospital de internamento dos pacientes, 96,2\% encontravam-se em hospitais públicos da Rede. Após o internamento, 33,1\% dos protocolos foram iniciados em até $24 \mathrm{~h}$ (Tabela 2).

Tabela 2 - Perfil clínico e de hospitalização do potencial doador. Macrorregional Petrolina. Petrolina, Pernambuco, Brasil - 2013-2017 (N=524)

\begin{tabular}{|c|c|c|}
\hline Variáveis & $\mathbf{n}$ & $\%$ \\
\hline \multicolumn{3}{|l|}{ Causa da Morte Encefálica $(n=524)$} \\
\hline Trauma Cranioencefálico & 177 & 33,9 \\
\hline Acidente Vascular Encefálico & 146 & 27,9 \\
\hline Hemorragia Subaracnoidea & 92 & 17,6 \\
\hline Perfuração por arma de fogo & 11 & 2,1 \\
\hline Tumor no sistema nervoso central & 10 & 1,9 \\
\hline Outras causas & 88 & 16,6 \\
\hline \multicolumn{3}{|l|}{ Hospital $(n=524)$} \\
\hline Público & 504 & 96,2 \\
\hline Privado & 20 & 3,8 \\
\hline \multicolumn{3}{|c|}{$\begin{array}{l}\text { Tempo de internamento até diagnóstico } \\
\text { de Morte Encefálica }(n=513)\end{array}$} \\
\hline Até 24 horas & 170 & 33,1 \\
\hline $25-48$ horas & 138 & 26,9 \\
\hline $49-72$ horas & 74 & 14,4 \\
\hline $73-96$ horas & 39 & 7,6 \\
\hline$>$ que 96 horas & 92 & 17,9 \\
\hline
\end{tabular}

Fonte: Elaboração própria.

Para a conclusão do protocolo, é necessária a realização de dois exames clínicos e exame complementar, de acordo com a idade, em conformidade com a legislação vigente. Em conformidade com os prontuários analisados, foram concluídos 86,8\% dos protocolos. Um total de 69 protocolos não foi concluído. Destes, 98,5\% foi devido à parada cardiorrespiratória entre as avaliações.

A parada cardiorrespiratória não é indicativa de interrupção ou não abertura do protocolo. Por vezes, pode ser a causa da ME, acontecendo antes do início do processo. Assim, identificou-se a ocorrência de 13 (2,5\%) paradas cardiorrespiratórias antes do início do protocolo. Entretanto, esses casos passaram pelo processo de reanimação cardiopulmonar (RCP) com êxito e foi possível iniciar o protocolo, pois os parâmetros eram viáveis para sua condução. O PCR foi registrado após protocolo aberto em 81 (15,6\%) casos, porém o diagnóstico de ME foi concluído, uma vez que o paciente foi reanimado e não houve a falência dos órgãos.

Foram concluídos 455 protocolos, todos com resultados conclusivos para ME. Deste quantitativo, foram realizadas 379 entrevistas com os familiares, pois os demais casos foram contraindicados para doação de órgãos, não sendo necessária a entrevista. O motivo mais prevalente de contraindicação da doação referia-se às condições clínicas dos pacientes (69,4\%). Apenas 6,6\% de pacientes apresentavam sorologia positiva para HIV ou hepatites, sendo também contraindicados à doação de órgãos. Das entrevistas realizadas, mais da metade $(53,5 \%)$ dos familiares aceitou a doação de órgãos e tecidos (Tabela 3). 
Tabela 3 - Processo de doação de órgãos. Macrorregional Petrolina. Petrolina, Pernambuco, Brasil 2013-2017 (N=524)

\begin{tabular}{|c|c|c|}
\hline Variáveis & $\mathbf{n}$ & $\%$ \\
\hline \multicolumn{3}{|c|}{ Protocolo de Morte Encefálica concluído $(n=524)$} \\
\hline Sim & 455 & 86,8 \\
\hline Não & 69 & 13,2 \\
\hline \multicolumn{3}{|l|}{ Motivo da não conclusão do protocolo $(n=69)$} \\
\hline Parada cardiorrespiratória entre avaliações & 68 & 98,5 \\
\hline Ausência de exames complementares & 1 & 1,5 \\
\hline \multicolumn{3}{|l|}{ Parada cardiorrespiratória $(\mathrm{n}=524)$} \\
\hline Não & 430 & 81,9 \\
\hline Sim, depois da abertura do protocolo & 81 & 15,6 \\
\hline Sim, antes da abertura do protocolo & 13 & 2,5 \\
\hline \multicolumn{3}{|l|}{ Entrevista familiar $(n=455)$} \\
\hline Sim & 379 & 83,3 \\
\hline Não & 76 & 16,7 \\
\hline Paciente sem condições clínicas & 54 & 71 \\
\hline Comorbidades do paciente & 7 & 9,2 \\
\hline Sorologia Positiva & 5 & 6,6 \\
\hline Neoplasias & 4 & 5,3 \\
\hline Disfunção múltiplos de órgãos & 4 & 5,3 \\
\hline Sepse & 2 & 2,6 \\
\hline \multicolumn{3}{|l|}{ Resultado das entrevistas familiar $(n=379)$} \\
\hline Positiva & 203 & 53,5 \\
\hline Negativa & 176 & 46,4 \\
\hline
\end{tabular}

Fonte: Elaboração própria.

\section{Discussão}

No presente estudo, as faixas etárias mais predominantes foram de 21 a 40 e 41 a 60 anos, evidenciando uma população de adultos em idade economicamente ativa. Pesquisas recentes mostram resultados similares com faixa etária prevalente entre 20 e 60 anos $^{(6-8)}$. Pacientes acima de 60 anos apresentam frequentemente maior prevalência de comorbidades e, por conta disso, menor tendência para serem doadores, o que fundamenta o predomínio de PD mais jovens. Entretanto, estudos apontam um aumento na idade do PD, o que pode ser justificado pelo envelhecimento da população, no caso do Brasil, e da flexibilização dos parâmetros clínicos para a inserção de possíveis doadores ${ }^{(9-10)}$.

Quanto ao sexo, houve predominância do sexo masculino, corroborando outros estudos com a mesma população ${ }^{(6-11)}$. De acordo com o Ministério da Saúde, os homens morrem mais cedo, principalmente por causas externas, são mais suscetíveis às doenças crônicas e procuram menos os serviços de saúde ${ }^{(12)}$. A literatura confirma os resultados deste estudo, ao identificar maior incidência de mortalidade e consequentemente maior ocorrência para PD em pessoas do sexo masculino ${ }^{(6-11)}$.

Nos EUA, de acordo com dados do Organ Procurement and Transplantation Network, em 2018, as faixas etárias mais predominantes foram de 18 a 34 anos, 35 a 49 anos e 50 a $63 \operatorname{anos}^{(13)}$. Além disso, o sexo prevalente entre os potenciais doadores foi o masculino, mostrando semelhança entre o perfil dos PD do estudo em questão e o encontrado neste estudo.

Dentre as principais causas de ME, encontram-se o Trauma Crânio Encefálico (TCE) seguido do Acidente Vascular Encefálico (AVE). Esses dados divergem de alguns achados ${ }^{(9,14-15)}$, 
que mostram o AVE como principal causa de ME. Esses estudos enfatizam uma mudança no perfil do doador, o que pode ser justificado pelo processo de envelhecimento da população atrelado ao aumento de doenças crônicas não transmissíveis, que se configuram como principais causas para o $\mathrm{AVE}^{(9)}$.

O trauma crânio encefálico (TCE) e causas cerebrovasculares também ganham destaque em outros países, como EUA e Espanha, sendo a segunda e terceira causas de morte, respectivamente. Entretanto, a principal causa de morte entre os potenciais doadores, no ano de 2018, nos EUA, foi anóxia, demonstrando uma diferença no perfil de mortalidade entre os países ${ }^{(13)}$.

De acordo com estudo realizado nos EUA, entre os anos de 2000 e 2015, as causas cerebrovasculares predominavam no perfil de mortalidade. No entanto, uma possível modificação no manejo dos fatores de risco que levam às doenças crônicas não transmissíveis tem justificado as mudanças que têm ocorrido nesse perfil $^{(16)}$.

Um importante dado deste estudo, presente também em outra pesquisa, foi a prevalência do TCE no sexo masculino, o que pode ser justificado pelo maior envolvimento de homens em violências e acidentes de trânsito ${ }^{(6)}$. Essa mesma associação esteve presente nos dados internacionais supracitados ${ }^{(13)}$.

A maioria dos PD deste estudo deu entrada em hospitais públicos, reforçando que grande parte da população brasileira depende do Sistema Único de Saúde e, devido à gravidade do quadro, necessita de cuidados de alta complexidade, os quais também são ofertados nessas instituições ${ }^{(17)}$.

Neste estudo, o tempo do internamento até a conclusão do diagnóstico de ME registrou variação entre 24 horas e mais de 96 horas. Isso ocorre devido ao processo assistencial para manutenção da vida do paciente crítico, bem como às realizações de exames clínicos e complementares recomendados pelo Conselho Federal de Medicina para confirmação da $\mathrm{ME}^{(2)}$. Entretanto, o tempo do processo de doação pode interferir na qualidade dos enxertos ofertados, comprometendo a sobrevida desses. Quanto menor o tempo de duração do processo, melhor a sobrevida desses órgãos ${ }^{(18)}$.

O Conselho Federal de Medicina estabelece que, para o fechamento do protocolo de ME, são necessários dois exames clínicos, realizados por médicos diferentes, e pelo menos um exame complementar $^{(2)}$. No presente estudo, houve alto número de protocolos concluídos, confirmando o diagnóstico de morte encefálica, o cumprimento da legislação e a seriedade na condução desses casos.

A não conclusão dos demais protocolos teve como principal motivo a ocorrência de PCR entre as avaliações. A PCR e a instabilidade hemodinâmica são intercorrências comuns em pacientes que estão evoluindo para o quadro de morte encefálica. Para que ocorra a conclusão do protocolo e a efetivação da doação de órgãos, é imprescindível a manutenção dos órgãos e tecidos para assegurar a sobrevida. Caso contrário, poderá haver a falência dos enxertos, inviabilizando o transplante ${ }^{(6)}$.

Em um estudo realizado na Itália, pôde-se observar a elegibilidade de órgãos em pacientes pós-RCP. Verificou-se que, de 112 pacientes, $56 \%$ tiveram seus órgãos doados e esses enxertos atingiram boa recuperação funcional ${ }^{(19)}$. Tal estudo demonstra o quanto é importante a assistência de qualidade ao paciente crítico, bem como a efetiva manutenção dos órgãos, pois, mesmo após a RCP, permanece alto o potencial para um indivíduo tornar-se doador ${ }^{(19)}$.

Entre as entrevistas familiares, 84\% foram efetivadas. A falta de condições clínicas do paciente e taxas alteradas ou exames de imagens indicativos de órgãos comprometidos foram os principais motivos que impediram a realização das entrevistas. Além disso, a sorologia positiva para HIV e Hepatites, disfunção de múltiplos órgãos, infecções e neoplasias também motivaram o impedimento. Segundo as Diretrizes elaboradas pela Associação de Medicina Intensiva Brasileira (AMIB) e as recomendações da Associação Brasileira de Transplante de Órgãos (ABTO), são consideradas contraindicações absolutas para doação de órgãos: presença de sepse não 
controlada clinicamente, infecções e neoplasias em que o risco de transmissão supera a possibilidade de benefícios dos potenciais receptores ${ }^{(4)}$.

Das entrevistas realizadas, $53,5 \%$ tiveram como resultado a autorização para a doação de órgãos e 46,4\% a negativa. Este número é maior que a média nacional de negativas familiares em $2018^{(1)}$.

Esses dados permitiram a identificação de que contraindicações clínicas e recusa familiar são fatores que provocam uma postura desfavorável à doação, sendo a última, a principal causa das não efetivações, caracterizando-se como causa modificável ${ }^{(20)}$. Isso reforça a importância de uma equipe qualificada para atuar nesse momento, ainda que seja considerado algo difícil e que envolve importante carga emocional por parte dos entrevistadores ${ }^{(21)}$. Esses dados referentes à recusa familiar corroboram o encontrado em uma pesquisa realizada na região Sul do país em $2017^{(20)}$.

É importante lembrar que a mudança recente da legislação brasileira trouxe novas orientações para a realização do diagnóstico de $\mathrm{ME}^{(2)}$, como a regulação do tempo entre as avaliações e a obrigatoriedade da comunicação prévia e adequada da má notícia para os familiares, fazendo com que os protocolos sejam concluídos de forma mais rápida e que a família esteja ciente de todas as etapas do diagnóstico.

A pesquisa realizada apresentou limitações na apresentação de algumas variáveis, devido à ausência de informações nos prontuários analisados.

\section{Conclusão}

Foi possível identificar que os potenciais doadores de órgãos da macrorregional em estudo, em sua maioria, são indivíduos do sexo masculino, das faixas etárias entre 21 e 40 e 41 e 60 anos de idade, com o trauma crânio encefálico como principal causa de morte encefálica. Esses pacientes foram internados predominantemente em hospitais públicos, permanecendo nessas instituições em torno de 24 horas até o diagnóstico definitivo de ME. Os protocolos de ME foram concluídos em sua maioria, e a entrevista familiar foi positiva para doação de órgãos em grande parte dos casos.

O processo de doação de órgãos ainda não é bem compreendido pela população, gerando dúvidas e inseguranças quanto à tomada de decisão. O estudo proporcionou melhor compreensão situacional e sinalizou a necessidade de discutir a temática da doação. Portanto, políticas de educação permanente acerca do tema, envolvendo profissionais de saúde e a população em geral, são indicadas para incentivar a doação de órgãos e tecidos, tendo em vista que a efetivação depende, em grande parte, do processo de doação e da autorização familiar.

Assim, conhecer o cenário do processo de doação de órgãos é de fundamental importância para os profissionais dos serviços de saúde, uma vez que oferece subsídios para uma assistência de qualidade, visando a manutenção da qualidade dos órgãos oferecidos, bem como o aumento do número de doações efetivadas.

Sugerem-se novos estudos para conhecer o cenário após as mudanças propostas na lei, que avancem no aprofundamento das análises de seus impactos, principalmente das causas para a não efetivação da doação de órgãos.

\section{Colaborações:}

1 - concepção, projeto, análise e interpretação dos dados: Christielle Lidiane Alencar Marinho, Ana Isabel Cezário de Carvalho Conceição e Flávia Emília Cavalcanti Valença Fernandes;

2 - redação do artigo e revisão crítica relevante do conteúdo intelectual: Christielle Lidiane Alencar Marinho, Ana Isabel Cezário de Carvalho Conceição, Alana Mirelle Coelho Leite e Joice Requião Costa de Santana;

3 - aprovação final da versão a ser publicada: Christielle Lidiane Alencar Marinho, Alana Mirelle Coelho Leite e Joice Requião Costa de Santana. 


\section{Referências}

1. Associação Brasileira de Transplante de Órgãos. Registro Brasileiro de Transplante 2018 [Internet]. Brasília; 2018 [cited 2019 Jun 25]. Available from: http://www.abto.org.br/abtov03/Upload/file/ RBT/2018/Lv_RBT-2018.pdf

2. Brasil. Conselho Federal de Medicina. Resolução n. 2.173, de 23 de novembro de 2017. Define os critérios do diagnóstico de morte encefálica ]Internet]. Brasília; 2017 [cited 2018 Jan 16]. Available from: https://sistemas.cfm.org.br/ normas/visualizar/resolucoes/BR/2017/2173

3. Brasil. Lei n. 10.211, de 23 de março de 2001. Altera os dispositivos da Lei n. 9.434, de 4 de fevereiro de 1997, que dispõe sobre a remoção de órgãos, tecidos e partes do corpo humano para fins de transplantes e tratamento [Internet]. Brasília; 2001 [cited 2018 Feb 2]. Available from: http://www. planalto.gov.br/ccivil_03/leis/LEIS_2001/L10211. htm

4. Westphal GA, Garcia VD, Souza RL, Franke CA, Vieira KD, Birckholz VR. Diretrizes para avaliação e validação do potencial doador de órgãos em morte encefálica. Rev Bras Ter Intensiva. [Internet]. 2016 [cited 2018 Nov 18];28(3):220-55. Available from: http://www.scielo.br/pdf/rbti/v28n3/0103507X-rbti-28-03-0220.pdf

5. Russo FP, Ferrarese A, Zanetto A. Recent advances in understanding and managing liver transplantation. F1000Research. 2016;1(3):1-8. DOI: https://doi. org/10.12688/f1000research.8768.1

6. Barreto SB, Santana RJB, Nogueira EC, Fernandez BO, Brito FPG. Fatores relacionados à não doação de órgãos de potenciais doadores no estado de Sergipe, Brasil. Rev Bras Pesqui Saúde [Internet]. 2016 [cited 2018 Nov 25];18(3):40-8. Available from: http://periodicos.ufes.br/RBPS/article/view/15741

7. Hahnenkamp K, Bohler K, Wolters $\mathrm{H}$, Wiebe K, Schneider D, Schmidt HHJ. Organ-Protective Intensive Care in Organ Donors. Deutsches Aerzteblatt Online. 2016 [cited 2019 Jun 20];113:552-8. Available from: https://www.ncbi. nlm.nih.gov/pmc/articles/PMC5015577/

8. Rodrigues TB, Vasconcelos MIO, Brito MCC, Sales DS, Silva RCC, Souza AMA. Perfil de potenciais doadores de órgãos em hospital de referência. Rev Rene [Internet]. 2013 [cited 2018 Dec 10];14(4):713-9. Available from: http://www. periodicos.ufc.br/rene/article/view/3529
9. Freire ILS, Silva MF, Gomes ATL, Dantas BAS, Torres GV. Caracterização dos potenciais doadores e estrutura de unidades hospitalares que desenvolvem o transplante. Ciênc Cuid Saúde [Internet]. 2015 [cited 2018 Dec 20];14(3):1281-9. Available from: http://www.periodicos.uem.br/ojs/ index.php/CiencCuidSaude/article/view/22819

10. Associação Brasileira de Transplante de Órgãos. Dados numéricos da doação de órgãos e transplantes realizados por estado e instituição no período: janeiro/dezembro 2012. Registro Brasileiro de Transplantes 2012 [Internet]. São Paulo; 2012 [cited 2018 Feb 3]. Available from: http://www.abto.org.br/abtov03/upload/file/ RBT/2012

11. Gois RS, Galdino MJ, Pissinati OS, Pimentel RR, Carvalho MD, Haddad MC. Efetividade do processo de doação de órgãos para transplantes. Acta Paul Enferm [Internet]. 2017 [cited 2019 Jan 10];30(6):621-7. Available from: http://www.scielo.br/scielo.php?script=sci_ abstract\&pid=S010321002017000600621\&lng=en \&nrm=iso\&tlng=pt

12. Brasil. Ministério da Saúde. Fundação Osvaldo Cruz. Instituto Nacional de Saúde da Mulher, da Criança e do Adolescente Fernandes Figueira. Perfil da situação de saúde do homem no Brasil 2012 [Internet]. Brasília; 2014 [cited 2018 fev 3]. Available from: http://portalarquivos2.saude.gov. br/images/pdf/2014/maio/21/CNSH-DOC-Perfilda-Situa----o-de-Sa--de-do-Homem-no-Brasil.pdf

13. United States of America. Department of Health \& Human Services. Organ Procurement and Transplantation Network. Data. Waiting list candidates 2018 [Internet]. Richmond, VA; 2018 [cited 2019 Jun 29]. Available from: https://optn. transplant.hrsa.gov/

14. Souza BSJ, Lira GG, Mola R. Notificação da morte encefálica em ambiente hospitalar. Rev Rene [Internet]. 2015 [cited 2019 Jan 15];16(2):194-200. Available from: http://periodicos.ufc.br/rene/ article/view/2705

15. Rodrigues SLM, Ferraz Neto JBE, Sardinha LAC, Araujo S, Zambelli HJL, Boin IFSF, et al. Perfil de doadores efetivos do serviço de procura de órgãos e tecidos. Rev bras ter intensiva. 2014;26(1):21-7. DOI: $10.5935 / 0103-507 x .20140004$

16. Yang Q, Tong X, Schieb L, Vaughan A, Gillespie C, Wiltz JL, et al. Vital Signs: Recent Trends in Stroke Death Rates - United States, 2000-2015. MMWR 
Morb Mortal Wkly Rep [Internet]. 2017 [cited 2019 Jun 10];66(35):933-9. Available from: https://www. cdc.gov/mmwr/volumes/66/wr/mm6635e1.htm

17. Pessoa LR, Santos IS, Machado JP, Martins ACMM, Lima CRA. Realocar a oferta do SUS para atender problemas do futuro: o caso do trauma no Brasil. Saúde Debate [Internet]. 2016 [cited 2019 Jun 10];40(110):9-19. Available from: http://www.scielo.br/scielo.php?pid=S0103$11042016000300009 \&$ script $=$ sci_abstract\&tlng=pt

18. Rocha DF, Nothen RR, Santos SR, Oliveira PC. Avaliação do tempo de realização do diagnóstico de mortes encefálicas notificadas à Central de Transplantes do Rio Grande do Sul. Sci Med. 2015;25(3):1-5. DOI: $10.15448 / 1980-6108.2015 .3 .21328$

19. Casadioa MC, Coppo A, Vargioluc A, Villa J, Rotac M, Avalli L, et al. Organ donation in cardiac arrest patients treated with extracorporeal
CPR: A single centre observational study. Resuscitation. 2017;118:133-9. DOI: 10.1016/j. resuscitation.2017.06.001

20. Bonetti CE, Boes AA, Lazzari DD, Busana JA, Maestris E, Bresolin P. Organ and tissue donation and reasons for its non-realization. Rev Enferm UFPE Online. 2017;11(9):3533-41. DOI: 10.5205/ reuol.10620-94529-1-SM.1109sup201705

21. Fonseca PN, Tavares CMM. O manejo das emoções dos coordenadores em transplantes na realização da entrevista familiar para doação de órgãos. Rev Port Enferm Saúde Mental [Internet]. 2015 [cited 2019 Jun 30];spe(2):39-44. Available from: http://www.scielo.mec.pt/scielo.php?script=sci_ arttext\&pid=S1647-21602015000100007

Recebido: 25 de setembro de 2019

Aprovado: 3 de novembro de 2019

Publicado: 18 de dezembro de 2019

A Revista Baiana de Enfermagem utiliza a Licença Creative Commons - Atribuição-NãoComercial 4.0 Internacional. https://creativecommons.org/licenses/by-nc/4.0/ Este artigo é de acesso aberto distribuído sob os termos da Licença Creative Commons (CC BY-NC). Esta licença permite que outros remixem, adaptem e criem a partir do seu trabalho para fins não comerciais. Embora os novos trabalhos tenham de lhe atribuir o devido crédito e não possam ser usados para fins comerciais, os usuários não têm de licenciar esses trabalhos derivados sob os mesmos termos. 